ERRATUM

Erratum doi: https://doi.org/10.1007/s00376-020-2015-1

\title{
Erratum to: An Examination of the Predictability of Tropical Cyclone Genesis in High-Resolution Coupled Models with Dynamically Downscaled Coupled Data Assimilation Initialization
}

\author{
Mingkui LI ${ }^{1,2}$, Shaoqing ZHANG ${ }^{1,2,3,4}$, Lixin WU ${ }^{1,2}$, Xiaopei LIN $^{1,2}$, Ping CHANG ${ }^{3,5}$, \\ Gohkan DANABASOGLU ${ }^{3,6}$, Zhiqiang $\mathrm{WEI}^{2}$, Xiaolin $\mathrm{YU}^{1,2}$, Huiqin $\mathrm{HU}^{2}$, \\ Xiaohui MA ${ }^{1,2}$, Weiwei MA ${ }^{1}$, Haoran $\mathrm{ZHAO}^{1}$, Dongning JIA ${ }^{2}$, Xin LIU ${ }^{7}$, \\ Kai $\mathrm{MAO}^{1}$, Youwei $\mathrm{MA}^{4}$, Yingjing JIANG ${ }^{4}$, Xue WANG ${ }^{1}$, \\ Guangliang $\mathrm{LIU}^{7}$, and Yuhu $\mathrm{CHEN}^{2}$
}

${ }^{1}$ Key Laboratory of Physical Oceanography, MOE, Institute for Advanced Ocean Study, College of Ocean and Atmosphere, Frontiers Science Center for Deep Ocean Multispheres and Earth System (DOMES), Ocean University of China, Qingdao 266100, China

${ }^{2}$ Pilot National Laboratory for Marine Science and Technology (QNLM), Qingdao 266237, China

${ }^{3}$ International Laboratory for High-Resolution Earth System Model and Prediction(iHESP), Qingdao 266237, China

${ }^{4}$ College of Oceanic and Atmospheric Sciences, Ocean University of China, Qingdao 266100, China

${ }^{5}$ Department of Oceanography, Texas A \& M University, College Station, Texas 77843, USA

${ }^{6}$ National Center for Atmospheric Research, Boulder, Colorado 80301, USA

${ }^{7}$ National Supercomputing Jinan Center, Jinan 250101, China

ESM to: Li, M. K., and Coauthors, 2020: An examination of the predictability of tropical cyclone genesis in highresolution coupled models with dynamically downscaled coupled data assimilation initialization. Adv. Atmos. Sci., 37(9), 939-950, https://doi.org/10.1007/s00376-020-9220-9.

In the figure legends of Fig. 8, the solid-dot and dashed lines should be switched over. The correct figure is shown below. We apologize for that.
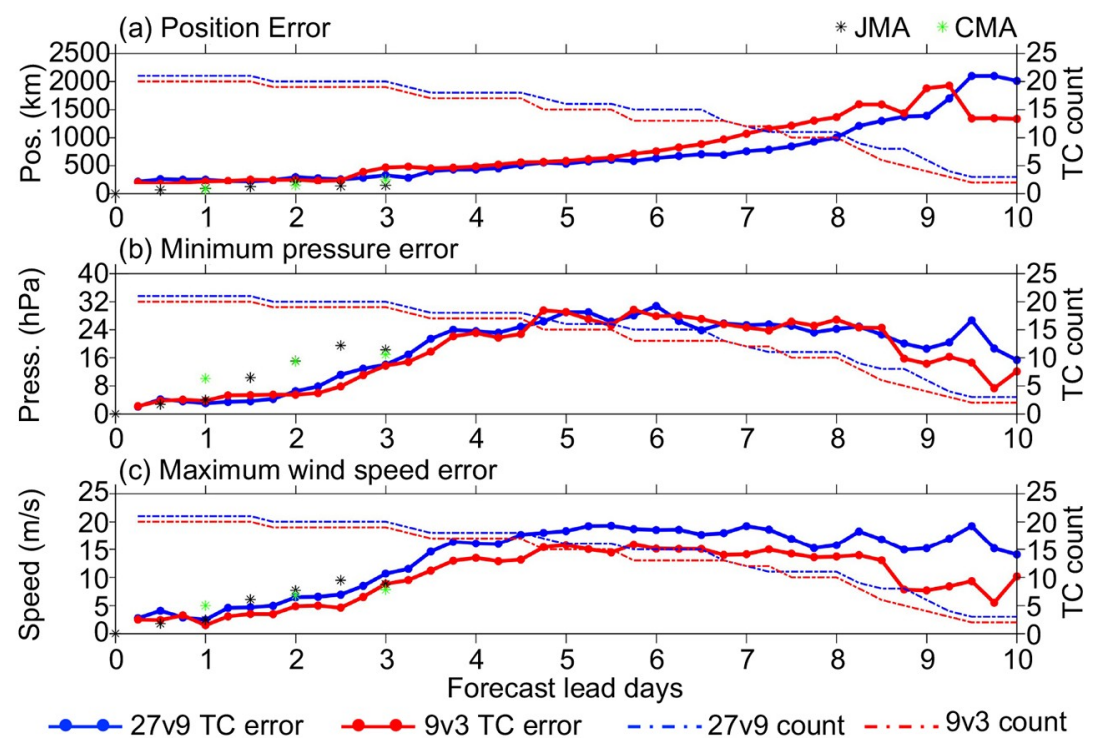

The online version of this original article can be found at https://doi.org/10.1007/s00376-020-9220-9 